\title{
Comparison of invasive treatment strategies in patients with non-ST elevation acute coronary syndrome: A systematic review and meta-analysis
}

Rikuta Hamaya, MD, MSc, a,b,c Yuan Ting Chang, MD, MPH, ${ }^{a}$ Api Chewcharat, MD, MPH, ${ }^{a}$ Nicholas Chiu, MD, MPH, ${ }^{\mathrm{a}}$ Taishi Yonetsu, MD, ${ }^{\mathrm{c}}$ Tsunekazu Kakuta, MD, PhD, ${ }^{\mathrm{d}}$ and Stefania Papatheodorou, MD, $\mathrm{PhD}^{\mathrm{a}}$

\section{ABSTRACT}

Objective: To compare the mortality associated with percutaneous coronary intervention $(\mathrm{PCl})$ and coronary artery bypass grafting (CABG) in patients with non-ST elevation acute coronary syndrome (NSTE-ACS).

Methods: We searched publications from PubMed, Embase, Web of Science, and the Cochrane Library from inception until December 23, 2020. All randomized clinical trials (RCTs) and observational studies comparing all-cause mortality after treatment with CABG versus $\mathrm{PCl}$ for patients with NSTE-ACS with minimum follow-up of 6 months were included. Restricted mean survival time (RMST) differences from RCTs and adjusted RMST differences from observational studies were computed by reconstructing time-to-event data from published Kaplan-Meier curves. Extracted hazard ratios (HRs) were also assessed as a secondary analysis.

Results: Our systematic review included an individual participant data analysis of 3 RCTs and 8 observational studies. A meta-regression showed a significant association between log-transformed HRs and duration of follow-up (-0.009 [95\% confidence interval (Cl), -0.002 to -0.016$]$ log-HR per 1-year longer follow-up; $P=.037$ ), suggesting a violation of the proportional hazard assumption. Analysis of 6 studies with available RMST data showed a significant inverse association between adjusted RMST differences and cutoff years (slope, $-0.028[95 \% \mathrm{Cl},-0.042$ to -0.013 ] year difference per 1-year longer cutoff; $P<.005$ ), suggesting a longer survival benefit in the CABG arm compared with the $\mathrm{PCl}$ arm with longer follow-up.

Conclusions: There was a trend toward a benefit of CABG compared with $\mathrm{PCI}$ in the longer follow-up in patients with NSTE-ACS. A large, well-designed RCT with longer follow-up is needed to obtain definitive evidence on this topic. (JTCVS Open 2021;8:323-35)

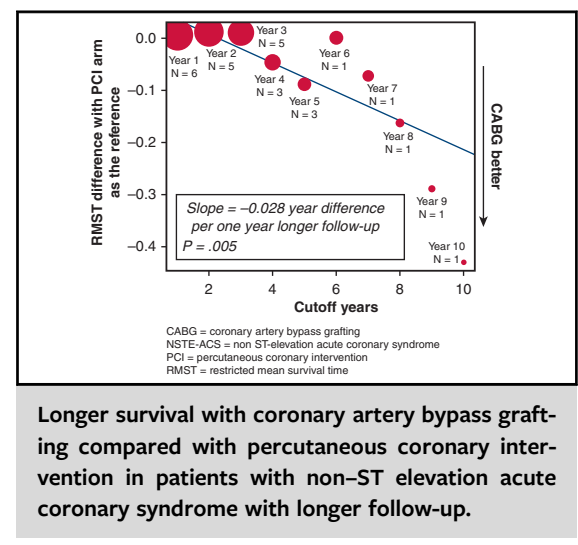

\section{CENTRAL MESSAGE}

The present meta-analysis suggests that treatment with coronary artery bypass grafting rather than percutaneous coronary intervention may be associated with better survival in patients with non-ST elevation acute coronary syndrome with a longer follow-up period.

\section{PERSPECTIVE}

The present meta-analysis suggests an advantage of treatment with coronary artery bypass grafting compared with percutaneous coronary intervention in patients with non-ST elevation acute coronary syndrome. A well-designed randomized controlled trial with longer follow-up is needed to obtain definitive evidence on this topic.

See Commentary on page 336.

\footnotetext{
From the a Department of Epidemiology, Harvard T. H. Chan School of Public Health, Boston, Mass; 'Division of Preventive Medicine, Brigham and Women's Hospital, Boston, Mass; 'Department of Cardiovascular Medicine, Tokyo Medical and Dental University, Tokyo, Japan; and ${ }^{\mathrm{d}}$ Division of Cardiovascular Medicine, Tsuchiura Kyodo General Hospital, Tsuchiura, Ibaraki, Japan.

This study was funded by the Brian and Heidi MacMahon Endowment fund. The activity of R.H. is funded by the Nakajima Foundation.

Received for publication Jan 4, 2021; accepted for publication Aug 20, 2021; available ahead of print Sept 29, 2021.
}

\footnotetext{
Address for reprints: Rikuta Hamaya, MD, MSc, Department of Epidemiology, Har vard T. H. Chan School of Public Health, 677 Huntington Ave, Boston, MA 02115 (E-mail: rhamaya@g.harvard.edu). 2666-2736

Copyright (C) 2021 The Author(s). Published by Elsevier Inc. on behalf of The American Association for Thoracic Surgery. This is an open access article under the CC BY-NC-ND license (http://creativecommons.org/licenses/by-nc-nd/4.0/). https://doi.org/10.1016/j.xjon.2021.08.028
} 


$\begin{array}{ll}\text { Abbreviations and Acronyms } \\ \text { CABG } & =\text { coronary artery bypass grafting } \\ \text { CI } & =\text { confidence interval } \\ \text { DES } & =\text { drug-eluting stent } \\ \text { HR } & =\text { hazard ratio } \\ \text { MVD } & =\text { multivessel disease } \\ \text { NSTE-ACS } & =\text { non-ST elevation acute coronary } \\ & \text { syndrome } \\ \text { PCI } & =\text { percutaneous coronary intervention } \\ \text { RCT } & =\text { randomized controlled trial } \\ \text { RMST } & =\text { restricted mean survival time }\end{array}$

Non-ST elevation acute coronary syndrome (NSTE-ACS), consisting of unstable angina pectoris and non-ST elevation myocardial infarction, is the most frequent manifestation of acute coronary syndrome. ${ }^{1}$ Previous studies have shown the benefit of routine invasive strategy in NSTE-ACS with percutaneous coronary intervention (PCI). ${ }^{2}$ The current guidelines recommend immediate invasive strategy (within 2 hours) for very-high-risk patients and early invasive (within 24 hours) or invasive strategy (within 72 hours) strategy for patients at other risk levels. ${ }^{3,4}$ Complete revascularization is associated with better outcomes in the presence of multivessel disease (MVD), which is a common finding in patients with NSTE-ACS. ${ }^{5,6}$ Coronary artery bypass grafting $(\mathrm{CABG})$ often may be selected for this purpose. However, the optimal invasive treatment option in terms of long-term survival, CABG or PCI, has not yet been established.

An individual participant data meta-analysis of 3 randomized trials showed lower hazard ratios (HRs) for the composite outcome of all-cause death, myocardial infarction, and stroke in the CABG arm compared with PCI arm. ${ }^{7}$ The only meta-analysis comparing CABG and PCI in patients with NSTE-ACS published thus far, this analysis was limited by inadequate power to compare all-cause mortality between groups, with a total sample size of 1246 patients (634 in the CABG arm and 612 in the PCI arm) and 121 events, with an HR of 0.81 (95\% confidence interval [CI], 0.57-1.16) favoring CABG. No additional large randomized controlled trials (RCTs) have been conducted to date. A recent observational study of 5112 patients showed favorable 10-year mortality after CABG compared with PCI after adjustment of confounders. ${ }^{8}$ However, another large prospective cohort study based on registry data demonstrated lower 3-year survival after CABG in patients with NSTE-ACS and MVD' ${ }^{9}$; as such, evidence is conflicting.

We conducted a systematic review and meta-analysis of available randomized and nonrandomized studies to determine which therapeutic approach is associated with lower mortality in patients with NSTE-ACS. We focused on evidence from RCTs and observational studies in which the treatment indication bias was appropriately accounted for using adjusted estimates. The present evidence will add overall guidance of current therapeutic options, not informing individual decisions, which should be tailored in all cases, ideally based on multidisciplinary consultation. ${ }^{10,11}$

\section{METHODS}

\section{Literature Search and Selection Criteria}

The protocol of this study followed the Preferred Reporting Items for Systemic review and Meta-Analysis Protocols (PRISMA-P). We searched publications from PubMed, Embase, Web of Science, and the Cochrane Library from inception until December 23, 2020, without any language restriction. The Medical Subject Heading (MeSH) terms "non-ST elevated myocardial infarction," "percutaneous coronary intervention," "coronary artery bypass," and corresponding terms and synonyms were used during the search process (Appendix E1).

Original studies with the following information were included: (1) treatment arms including PCI with either bare-metal stents or drug-eluting stents (DES), excluding balloon-only angioplasty, and CABG, either onpump or off-pump; (2) outcomes including all-cause mortality; (3) effect estimates of relative risk, odds ratio, or HR, adjusted for potential confounders; and (4) a minimum follow-up of 6 months. Types of studies included RCT, cohort, case-control, and case-cohort.

Patient informed written consent for publication of the study data was not obtained for this systematic review and meta-analysis. This study has been registered at PROSPERO (registration CRD42019135211).

\section{Data Extraction}

After removal of duplicates, a total of 16,046 studies were retrieved. Titles and abstracts were screened independently by 2 researchers. Accordingly, 402 full-text articles were reviewed thoroughly for eligibility. Disagreements were reviewed by an experienced cardiologist (R.H.) and resolved by unanimous consensus after discussion. Data from each selected article were extracted by 2 independent reviewers and checked centrally for plausibility and integrity. The search algorithm is shown in Figure 1. First author, journal, study design, sample size, inclusion criteria, follow-up duration, measure of association, confounders, and other basic characteristics were extracted. For studies that provided only incidence as their main results, we derived the relative risks from the data presented in the articles to allow appropriate pooling with effect estimates from other studies.

\section{Data Reconstruction From Kaplan-Meier Curves and Restricted Mean Survival Time Analysis}

Owing to the potential violation of the proportional hazard assumption in the Cox proportional regressions, we conducted a meta-analysis of restricted mean survival time (RMST) using time-to-event data reconstructed from digitally captured Kaplan-Meier curves. ${ }^{12,13}$ In brief, Kaplan-Meier curves of the RCT population ${ }^{7}$ and propensity score-matched populations from observational studies ${ }^{8,9,14-16}$ were digitally captured, and the time and survival probability coordinates were measured using WebPlotDigitizer (https://automeris.io/WebPlotDigitizer). The individual patient time-toevent data were reconstructed based on the mathematical algorithm coded in $\mathrm{R}$ proposed by Guyot and colleagues. ${ }^{12}$ The number of patients at risk and total number of events also were entered into the algorithm when available.

Based on the reconstructed time-to-event data, the differences in RMSTs between the PCI and CABG arms were computed from the beginning of follow-up to the cutoff years (years $1-10$ by 1 year). RMST represents the average time to event over a fixed time period, which corresponds to the area under the Kaplan-Meier curve. ${ }^{13}$ We set the CABG arm as the 


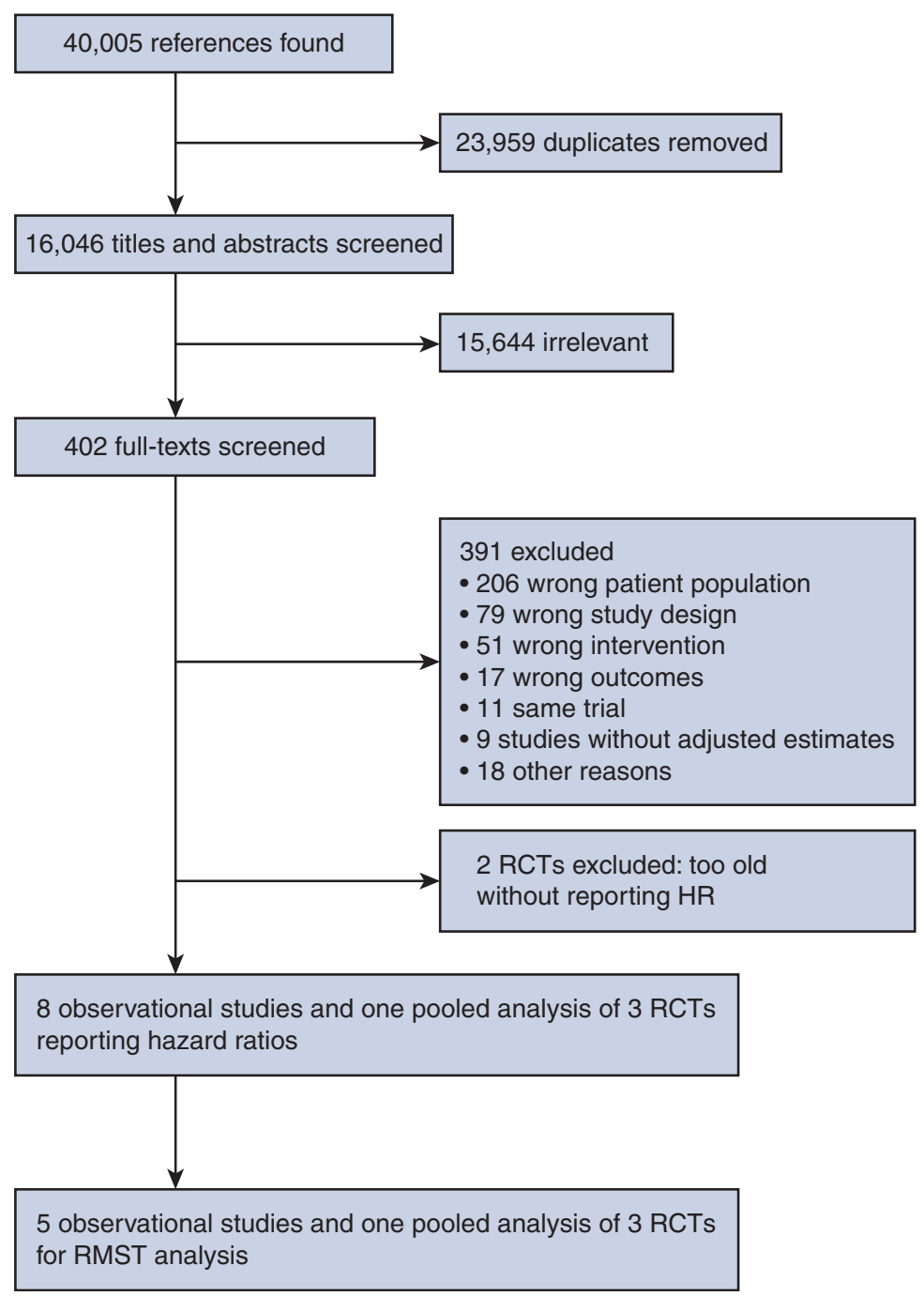

FIGURE 1. Study selection flowchart. $R C T$, Randomized controlled trial; $H R$, hazard ratio; $R M S T$, restricted mean survival time.

reference for RMST analysis; therefore, the differences in RMST can be interpreted as " $x$-year longer survival in the PCI arm compared with the CABG arm until the cutoff year on average."

We could not estimate RMSTs in the 3 observational studies, ${ }^{17-19}$ because the adjusted Kaplan-Meier curves were not published. We contacted the authors of these studies, but it was not possible to obtain these data. RMST analyses were added in the review process and not specified in the protocol.

\section{Data Analysis}

The primary outcome was all-cause mortality. The effect estimate of each study was transformed uniformly into the effect of CABG compared with PCI. Adjusted HRs from observational studies and unadjusted HRs from RCTs based on Cox proportional hazards models and the corresponding $95 \%$ CIs were extracted. These data were not included in the meta-analysis owing to the obvious violation of the proportional hazards assumption. We conducted random-effects meta-analysis of the differences in RMSTs at various cutoff years (year 1 to year 5) separately. Only 1 study ${ }^{8}$ was available for RMST analysis with a cutoff year of 6 to 10 .

Between-study variance was estimated by Sidik-Jonkman estimators. ${ }^{20}$ Cochran's Q test and the $I^{2}$ statistic were applied to evaluate the between-study heterogeneity. We performed a meta-regression to estimate the time-dependent relationship between RMST differences and the cutoff years, and between the log-transformed HRs and follow-up durations. We conducted sensitivity analyses using only observational studies and using only studies with a maximum follow-up of 5 years.

\section{Quality Assessment and Publication Bias}

A revised Cochrane risk-of-bias tool for randomized trials was used to evaluate the risk of bias for the RCTs. The assessment included the following components: (1) risk of bias arising from the randomization process, (2) risk of bias due to deviation from the intended interventions, (3) missing outcome data, (4) risk of bias in measurement of outcomes, and (5) risk of bias in selection of the reported results. For the observational studies, study quality was evaluated using the Newcastle-Ottawa Quality Assessment Scale, with a full score of 9, comprising 3 categories: selection, comparability, and exposure for case-control studies and outcome for cohort studies. In addition, we examined funnel plot asymmetry to detect possible publication bias. ${ }^{21}$ Egger's test was also applied to examine the small-study effects. To better understand the uncertainty of the pooled results and examine the influence of an individual estimate in our results, the leave-one-out method served as a sensitivity analysis. All statistical 


\begin{tabular}{|c|c|c|c|c|c|c|c|c|c|c|c|c|c|}
\hline $\begin{array}{c}\text { Author } \\
\text { (study name) }\end{array}$ & $\begin{array}{c}\text { Published } \\
\text { year }\end{array}$ & $\begin{array}{l}\text { Study } \\
\text { design }\end{array}$ & $\begin{array}{l}\text { Patient } \\
\text { group }\end{array}$ & $\begin{array}{c}\text { Study } \\
\text { quality* }\end{array}$ & $\begin{array}{l}\text { Mean } \\
\text { age, } y\end{array}$ & $\begin{array}{c}\text { Male } \\
\text { proportion }\end{array}$ & $\begin{array}{l}\text { Number of } \\
\text { PCI/CABG }\end{array}$ & $\begin{array}{l}\text { Proportion } \\
\text { of DES in } \\
\text { PCI arm }\end{array}$ & $\begin{array}{c}\text { Proportion } \\
\text { of DM }\end{array}$ & $\begin{array}{l}\text { Follow- } \\
\text { up, } \\
\text { mo }\end{array}$ & $\begin{array}{c}\text { Adjusted HR } \\
(\mathbf{9 5} \% \mathbf{C I}) \dagger\end{array}$ & $\begin{array}{l}\text { Statistical } \\
\text { methods for } \\
\text { adjusting } \\
\text { confounders }\end{array}$ & Adjusted confounders \\
\hline $\begin{array}{l}\text { Ahmed et al }^{14} \\
\text { (Korea Acute } \\
\text { Myocardial } \\
\text { Infarction } \\
\text { Registry) }\end{array}$ & 2012 & Cohort & $\begin{array}{l}\text { NSTEMI, } \\
\text { metabolic } \\
\text { syndrome, } \\
\text { MVD }\end{array}$ & Good & 64.9 & 0.64 & $693 / 82$ & 1.0 & 0.39 & 12 & $0.75(0.15-3.87)$ & $\begin{array}{l}\text { Propensity } \\
\text { score } \\
\text { matching }\end{array}$ & $\begin{array}{l}\text { Determined by univariate } \\
\text { screening (no details) }\end{array}$ \\
\hline $\begin{array}{c}\text { Ben-Gal et al }{ }^{17} \\
\text { (ACUITY) }\end{array}$ & 2015 & Cohort & $\begin{array}{l}\text { NSTE-ACS, } \\
\text { DM, MVD } \\
\text { involving } \\
\text { LAD }\end{array}$ & Good & 65.0 & 0.70 & $1349 / 423$ & 0.61 & 1 & 12 & $1.41(0.90-2.22)$ & $\begin{array}{l}\text { Outcome } \\
\text { regression }\end{array}$ & $\begin{array}{l}\text { Age, sex, insulin-treated } \\
\text { DM, previous CABG, } \\
\text { ST segment deviation } \\
\geq 1 \mathrm{~mm}\end{array}$ \\
\hline $\begin{array}{l}\text { Buszman et } \mathrm{al}^{9} \\
\text { (Milestone } \\
\text { registry) }\end{array}$ & 2014 & Cohort & $\begin{array}{l}\text { NSTE-ACS, } \\
\text { MVD at } \\
\text { least } \\
\text { involving } \\
\text { LAD } \\
\text { and RCA }\end{array}$ & Good & 64.7 & 0.71 & $3033 / 1553$ & 0.10 & 0.27 & 36 & $1.33(1.05-1.70)$ & $\begin{array}{l}\text { Propensity } \\
\text { score } \\
\text { matching }\end{array}$ & $\begin{array}{l}\text { "Baseline characteristics," } \\
\text { supposedly variables } \\
\text { listed in their Table 2: } \\
\text { age, sex, HT, } \\
\text { hypercholesterolemia, } \\
\text { DM, obesity, CHF, } \\
\text { CKD, PAD, current } \\
\text { smoking, previous MI, } \\
\text { previous CABG, } \\
\text { previous PCI, } \\
\text { NSTEMI, UAP, EF, } \\
\text { Euroscore, TIMI score, } \\
\text { Killip class, cardiac } \\
\text { arrest, angiographic } \\
\text { and lesion } \\
\text { characteristics }\end{array}$ \\
\hline Desperak et al ${ }^{15}$ & 2018 & Cohort & $\begin{array}{l}\text { NSTE-ACS, } \\
\text { MVD } \\
\text { involving } \\
\text { LAD }\end{array}$ & Good & 66.6 & 0.66 & $335 / 120$ & 0.39 & 0.39 & 36 & $1.06(0.53-2.13)$ & $\begin{array}{l}\text { Propensity } \\
\text { score } \\
\text { matching }\end{array}$ & $\begin{array}{l}\text { No details. The following } \\
P \text { values in the matched } \\
\text { cohort were }>.05 \text {; age, } \\
\text { sex, NSTEMI, HT, } \\
\text { previous MI, AF, prior } \\
\text { stroke, DM, smoking, } \\
\text { elevated cardiac } \\
\text { troponin-T, ST-segment } \\
\text { deviations, serum } \\
\text { creatinine, LVEF, } \\
\text { GRACE score, } \\
\text { Euroscore II, 3-vessel } \\
\text { CAD, left main disease }\end{array}$ \\
\hline
\end{tabular}




\begin{tabular}{|c|c|c|c|c|c|c|c|c|c|c|c|c|c|}
\hline $\begin{array}{c}\text { Author } \\
\text { (study name) }\end{array}$ & $\begin{array}{c}\text { Published } \\
\text { year }\end{array}$ & $\begin{array}{l}\text { Study } \\
\text { design }\end{array}$ & $\begin{array}{c}\text { Patient } \\
\text { group }\end{array}$ & $\begin{array}{c}\text { Study } \\
\text { quality* }\end{array}$ & $\begin{array}{l}\text { Mean } \\
\text { age, } y\end{array}$ & $\begin{array}{c}\text { Male } \\
\text { proportion }\end{array}$ & $\begin{array}{l}\text { Number of } \\
\text { PCI/CABG }\end{array}$ & $\begin{array}{c}\text { Proportion } \\
\text { of DES in } \\
\text { PCI arm } \\
\end{array}$ & $\begin{array}{c}\text { Proportion } \\
\text { of DM }\end{array}$ & $\begin{array}{l}\text { Follow- } \\
\text { up, } \\
\text { mo } \\
\end{array}$ & $\begin{array}{c}\text { Adjusted HR } \\
(95 \% \text { CI }) \dagger \\
\end{array}$ & $\begin{array}{l}\text { Statistical } \\
\text { methods for } \\
\text { adjusting } \\
\text { confounders }\end{array}$ & Adjusted confounders \\
\hline Freitas et $\mathrm{al}^{16}$ & 2019 & Cohort & NSTEMI & Good & 69.0 & 0.73 & $399 / 289$ & 0.70 & 0.41 & 60 & $0.63(0.40-0.98)$ & $\begin{array}{l}\text { Propensity } \\
\text { score } \\
\text { matching }\end{array}$ & $\begin{array}{l}\text { Age, sex, BMI, HT, } \\
\text { smoking, DM, } \\
\text { hypercholesterolemia, } \\
\text { severe pulmonary } \\
\text { disease, PAD, stroke/ } \\
\text { TIA, previous MI, } \\
\text { previous PCI/CABG, } \\
\text { LVEF, CCr, GRACE } \\
\text { strata, SYNTAX, } \\
\text { diseased vessels, LMD, } \\
\text { proximal LAD, } \\
\text { 3-vessel disease, } \\
\text { Euroscore II }\end{array}$ \\
\hline Jia et $\mathrm{al}^{18}$ & 2020 & Cohort & $\begin{array}{l}\text { NSTE- } \\
\text { ACS, MVD } \\
\text { (3-vessel } \\
\text { disease) }\end{array}$ & Good & 61.3 & 0.77 & $1589 / 1230$ & No description & 0.34 & 90 & $0.91(0.58-1.43)$ & $\begin{array}{l}\text { Outcome } \\
\text { regression }\end{array}$ & $\begin{array}{l}\text { Age, sex, DM, previous } \\
\text { MI, PAD, CKD, acute } \\
\text { MI or UAP, LVEF, } \\
\text { creatinine, CCr, } \\
\text { SYNTAX, LMD, } \\
\text { medication, } \\
\text { hemoglobin }\end{array}$ \\
\hline $\begin{array}{l}\text { Ram et } \mathrm{al}^{8} \\
\quad \text { (ACSIS) }\end{array}$ & 2019 & Cohort & NSTE-ACS & Good & 65.0 & 0.75 & $4327 / 785$ & No description & 0.39 & 120 & $0.46(0.30-0.69)$ & $\begin{array}{l}\text { Outcome } \\
\text { regression; } \\
\text { propensity } \\
\text { score } \\
\text { matching }\end{array}$ & $\begin{array}{l}\text { Age, sex, HT, smoking, } \\
\text { DM, 3-vessel CAD, } \\
\text { previous MI, renal } \\
\text { impairment, previous } \\
\text { stroke, CHF, and an } \\
\text { onsite cardiac surgery } \\
\text { unit }\end{array}$ \\
\hline $\begin{array}{l}\text { Ramanathan } \\
\text { et al }{ }^{19}\end{array}$ & 2017 & Cohort & $\begin{array}{l}\text { NSTE-ACS, } \\
\text { DM, MVD, } \\
\text { no LMD }\end{array}$ & Good & 66.5 & 0.74 & $1966 / 1051$ & 0.80 & 1 & 60 & $0.48(0.39-0.59)$ & $\begin{array}{l}\text { Outcome } \\
\text { regression } \\
\text { (excluding } \\
\text { first month) }\end{array}$ & $\begin{array}{l}\text { Sex and factors } \\
\text { determined by } \\
\text { univariate screening (no } \\
\text { detail) }\end{array}$ \\
\hline $\begin{array}{l}{\text { Chang et } \mathrm{al}^{7}} \\
\text { (BEST, } \\
\text { PRECOMBAT, } \\
\text { SYNTAX trials) }\end{array}$ & 2017 & $\mathrm{RCT}$ & $\begin{array}{l}\text { NSTE-ACS, } \\
\quad \text { MVD or } \\
\text { LMD }\end{array}$ & $\begin{array}{r}\text { Low risk } \\
\text { of bias }\end{array}$ & 64.6 & 0.72 & $612 / 634$ & 1.0 & 0.35 & 60 & $0.74(0.56-0.98)$ & $\begin{array}{l}\text { None (crude } \\
\text { analysis) }\end{array}$ & None \\
\hline
\end{tabular}

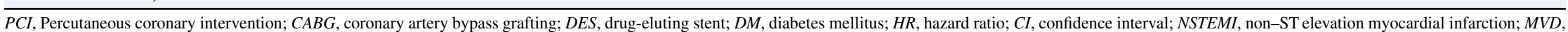
multivessel disease; $N S T E-A C S$, non-ST elevation acute coronary syndrome; $L A D$, left anterior descending artery; $R C A$, right coronary artery; $H T$, hypercholesterolemia; $C H F$, congestive heart failure; $C K D$, chronic kidney disease; N $P A D$, peripheral artery disease; $M I$, myocardial infarction; $U A P$, unstable angina pectoris; $E F$, ejection fraction; $T I M I$, thrombolysis in myocardial infarction; $A F$, atrial fibrillation; $L V E F$, left ventricular ejection fraction; $C A D$, cor-
onary artery disease; $B M I$, body mass index; $C C r$, creatinine clearance; $L M D$, left main disease; $R C T$, randomized controlled trial. *Quality was assessed by the Newcastle-Ottawa Quality Assessment for cohort studies categorized into good/fair/poor quality and the Cochrane risk of bias tool for randomized trials categorized into low/some concerns/high risk of bias. †HRs of mortality by PCI treatment with CABG treatment as the reference. 
analyses were performed with R version 3.5.2 (R Foundation for Statistical Computing, Vienna, Austria).

\section{RESULTS}

\section{Characteristics of the Included Studies}

A total of 8 observational studies in which adjusted HRs were reported, ${ }^{8,9,14-19} 2 \mathrm{RCTs},{ }^{22,23}$ and 1 pooled analysis of 3 RCTs (not duplicative of the 2 RCTs) ${ }^{7}$ were identified by our systematic search (Figure 1). However, the $2 \mathrm{RCTs}^{22,23}$ were very old (patient enrollment in 1997-1998 ${ }^{23}$ and 1995$2000^{22}$ ) and did not report HRs, so we excluded them from our analysis. One pooled analysis of RCTs ${ }^{7}$ was based on individual patient data but was not conclusive with respect to all-cause mortality. Therefore, we collectively analyzed this study along with other observational studies.

The total number of included patients in the present systematic review was 6167 in the CABG arm and 14,303 in the PCI arm. Table 1 summarizes the characteristics of the 9 included studies.

The year of publication ranged from the year 2012 to 2020 . Overall mean patient age was approximately 65 years with male proportion ranging from $64 \%$ to $77 \%$. Two studies $^{14,16}$ included only non-ST elevation myocardial infarction according to the current definition, and 7 studies $^{7,9,14,15,17-19}$ focused on MVD. The proportion of DES usage in the PCI arm was $100 \%$ in 2 studies, ${ }^{7,14}$ $60 \%$ to $80 \%$ in 3 studies, ${ }^{16,17,19}$ and $<40 \%$ in 2 studies, ${ }^{9,15}$ and unreported in 2 studies. ${ }^{8,18}$ The duration of follow-up ranged from 12 to 120 months. One study ${ }^{19}$ with a follow-up of 60 months reported adjusted HR excluding events at 1 month after treatment. All studies were deemed of good quality according to the Newcastle-Ottawa Quality Assessment or Cochrane risk-of-bias tool. One study ${ }^{15} \mathrm{did}$ not explicitly list the potential confounders used to compute the propensity score, while the demographic characteristics were largely balanced in the matched cohort.

\section{Evidence of the Violation of Proportional Hazard Assumption}

A meta-regression of 9 studies reporting adjusted HR showed a significant association between log-transformed HR and follow-up duration $(-0.009$ [95\% CI, -0.002 to $-0.016] \log$-HR per 1-year longer follow-up; $P=.037$ ) (Figure 2). The results indicated a favorable survival in the CABG arm with longer follow-up compared with shorter follow-up, reflecting the violation of the proportional hazards assumption. The adjusted HRs, summarized in Table 1, were not included in the meta-analysis because they were not valid owing to the violation of the proportional hazards assumption.

\section{Pooled RMST Differences at Various Cutoff Years}

Figure 3 summarizes the pooled RMST differences by random-effects models at cutoff year 1 to 10 based on 6

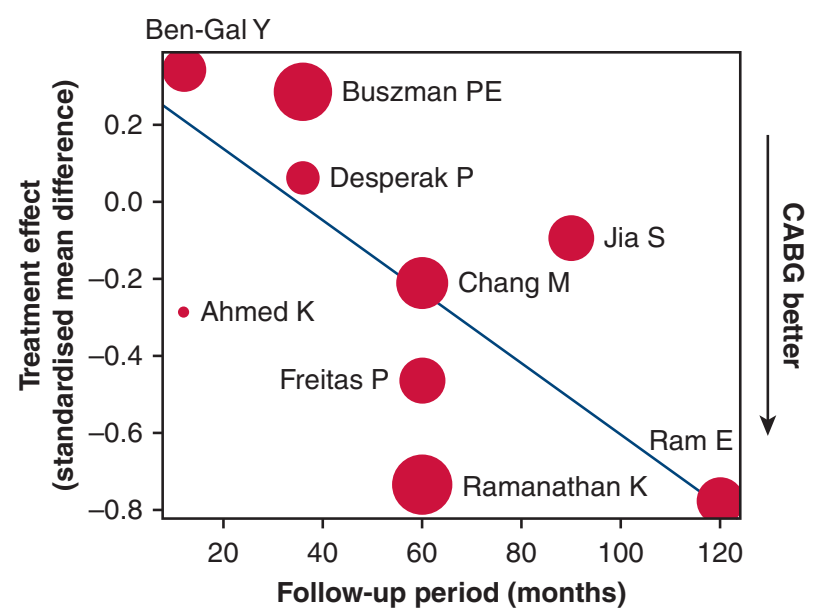

FIGURE 2. Meta-regression of log-transformed HRs by duration of follow-up. In this meta-regression of 9 studies, the $x$-axis and $y$-axis indicate follow-up duration and log-transformed hazard ratios (HRs), respectively. Each study was weighted by the inverse variance, represented by the circle area of each study. Significant inverse association was observed (slope, $-0.11 \log$-HR per 1-year longer follow-up; $P=.037$ ). $C A B G$, Coronary artery bypass grafting.

studies with available data. Compared with the CABG arm, on average the PCI arm had additional survival time of $0.006(95 \% \mathrm{CI},-0.012$ to 0.025$)$ year at year $1,0.012$ ( $95 \% \mathrm{CI},-0.058$ to 0.081$)$ year at year $2,0.01$ (95\% CI, -0.109 to 0.13$)$ year at year $3,-0.046(95 \% \mathrm{CI},-0.445$ to 0.352 ) year at year 4 , and $-0.088(95 \% \mathrm{CI},-0.572$ to $0.396)$ year 5 . The $I^{2}$ statistics were $0.44,0.62,0.65,0.67$, and 0.59 for cutoff years 1 to 5 , respectively, indicating moderate heterogeneity of the summary estimates. Analysis of a study with a 120-month follow-up ${ }^{8}$ showed longer survival in the PCI arm compared with the CABG arm by 0.001 ( $95 \% \mathrm{CI},-0.21$ to 0.211$)$ year at year $6,-0.072(95 \% \mathrm{CI}$, -0.331 to 0.186$)$ year at year $7,-0.163(95 \% \mathrm{CI},-0.473$ to 0.148$)$ year at year $8,-0.289(95 \% \mathrm{CI},-0.654$ to 0.076$)$ year at year 9 , and $-0.43(95 \% \mathrm{CI},-0.854$ to -0.007$)$ year at year 10. Meta-regression of the pooled RMST differences at years 1 to 5 and RMST differences in 1 study at years 6 to 10 indicated a significant inverse association of RMST differences and cutoff years (slope, -0.028 [95\% CI, -0.042 to -0.013] year difference per 1-year longer cutoff, $P=.005$ ) (Figure 4), suggesting a longer survival benefit in the CABG arm compared with the PCI arm with the longer follow-up.

\section{Sensitivity Analysis}

We observed similar results when analyzing only observational studies (Figures E1 and E2). In the meta-regression, the advantage of CABG compared with PCI was pronounced with longer follow-up (slope, -0.029 [95\% CI, -0.046 to -0.011] year difference per 1-year longer cutoff; $P=$.006). However, we did not observe a statistically 


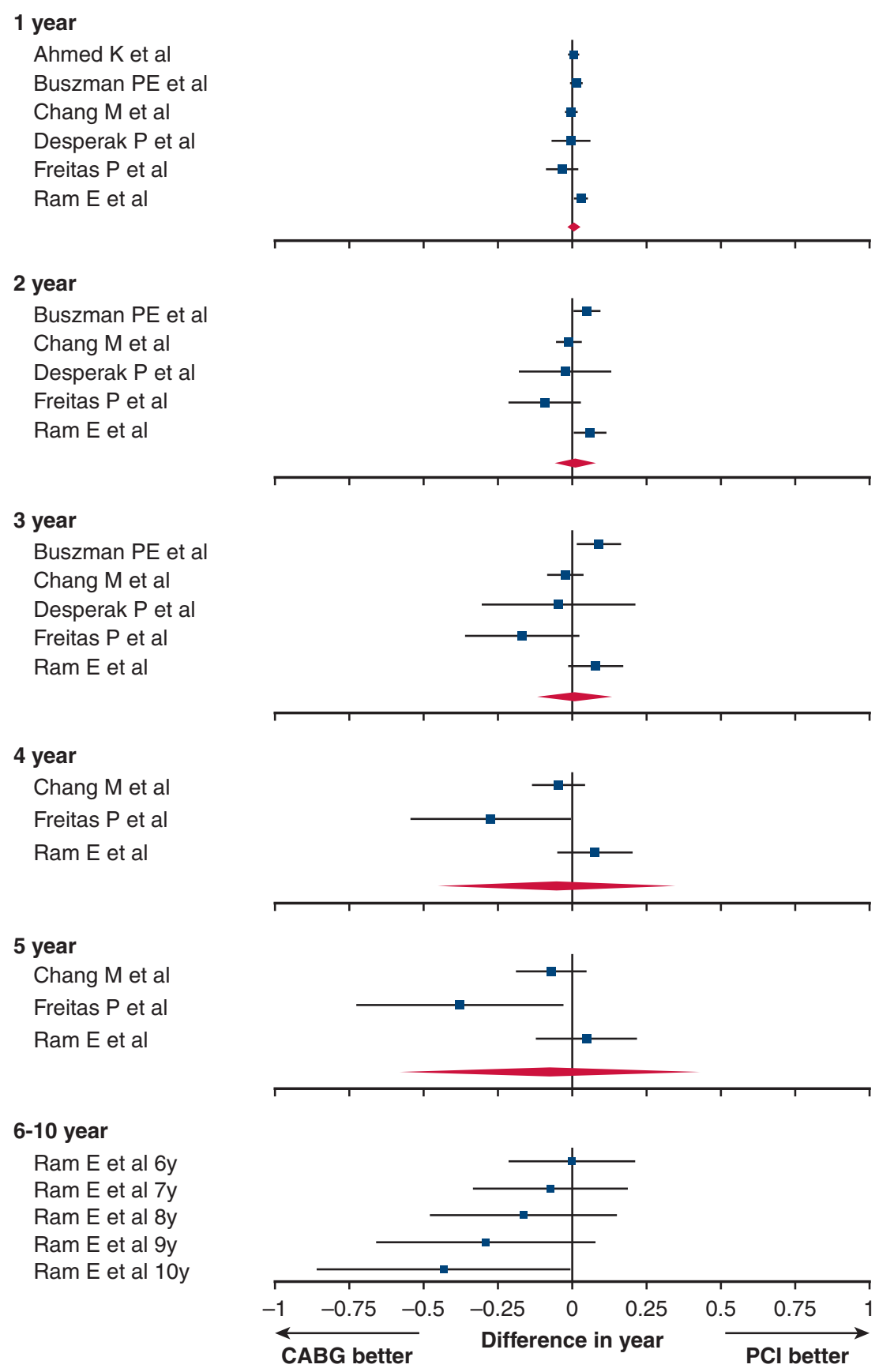

FIGURE 3. Pooled adjusted differences in adjusted restricted mean survival time (RMST) of mortality in patients with non-ST elevation acute coronary syndrome (NSTE-ACS) after percutaneous coronary intervention $(P C I)$ compared with coronary artery bypass grafting $(C A B G)$, based on 6 studies in which RMST data could be computed. The $x$-axis shows the average differences in survival by year until the cutoff year. The analyses were conducted with different cutoff years (years 1-10). The red diamonds represent the summary estimate in the RMST analysis with cutoff years 1 to 5 . The RMST analysis with cutoff at years 6 to 10 is based on a study by Ram and colleagues. ${ }^{8}$

significant association in studies with $\leq 5$-year follow-up, excluding the study by Ram and colleagues ${ }^{8}$ (slope, -0.009 [95\% CI, -0.034 to 0.017$]$ year difference per 1-year longer cutoff, $P=.35$ ) (Figure E3). This observation highlights the need for longer follow-up to meaningfully compare the prognostic impact of these treatment strategies.

\section{Insights Into HRs and Systematic Review}

The findings from the 3 studies that could not be leveraged for the RMST analysis might convey useful information. A study by Ramanathan and colleagues ${ }^{19}$ conducted in patients with diabetes with 60 months of follow-up strongly favored the $\mathrm{CABG}$ arm with long-term survival 


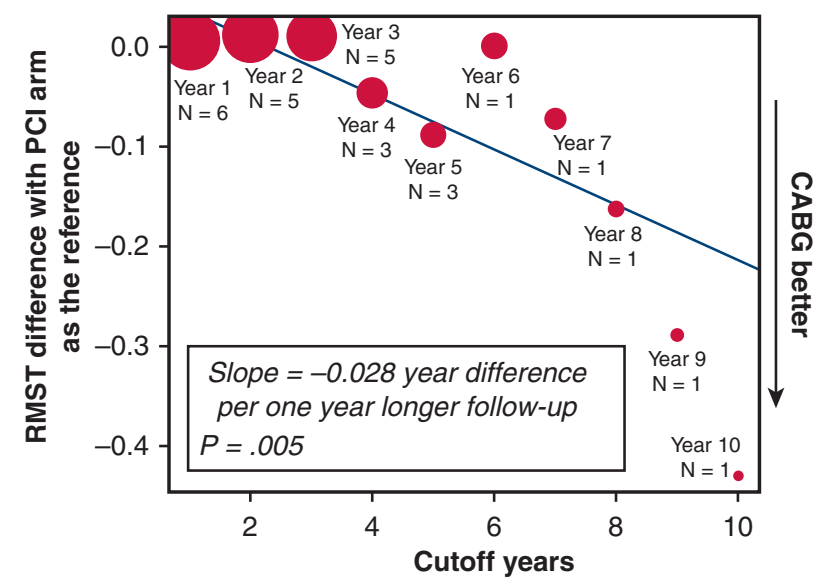

FIGURE 4. Meta-regression of differences in the pooled adjusted restricted mean survival time (RMST) with the percutaneous coronary intervention $(P C I)$ arm as the reference ( $y$-axis) in RMST cutoff years 1 to 10 ( $x$-axis), based on 6 studies in which RMST data could be computed. $N$ indicates the number of studies included in the analysis. Each analysis with different cutoff year was weighted by the inverse variance, represented by the circle area of each analysis. Significant inverse association was observed (slope, -0.028 year difference per 1-year longer cutoff; $P=.005) . C A B G$, Coronary artery bypass grafting.

(mortality risk after 1 month, $12.4 \%$ in the CABG arm $[n=1005]$ vs $22.3 \%$ in the PCI arm [ $n=1802]$ ), supporting the present proposed association of better survival after CABG compared with PCI with a longer follow-up period. A study by Ben-Gal and colleagues ${ }^{17}$ with 12 months of follow-up reported a null association with very few numbers of events in the matched cohort ( 9 of 163 in the CABG arm vs 11 of 163 in the PCI arm), contributing little information. Finally, a study by Jia and colleagues ${ }^{18}$ targeting 3-vessel disease with 90 months of follow-up reported a similar crude mortality risk ( 157 of 1230 in the CABG arm vs 209 of 1589 in the PCI arm). This is the only study not supporting the proposed association, which might be attributable in part to the target population with exclusive 3-vessel disease, potentially lower use of DES (no description of the proportion), and younger mean age of the study population (Table 1).

\section{Publication Bias Assessment}

We evaluated potential publication bias in the metaanalysis of adjusted HRs. The funnel plot was symmetrical by visual assessment (Figure E4), and Egger's test for small-study effects yielded a $P$ value of 0.66 , suggesting no evidence for significant small-study effects. However, the small number of the included studies $(n=9)$ might have led to the lower statistical power of these assessments, given the rule of thumb to perform publication bias tests when there are 10 or more studies to synthesize.

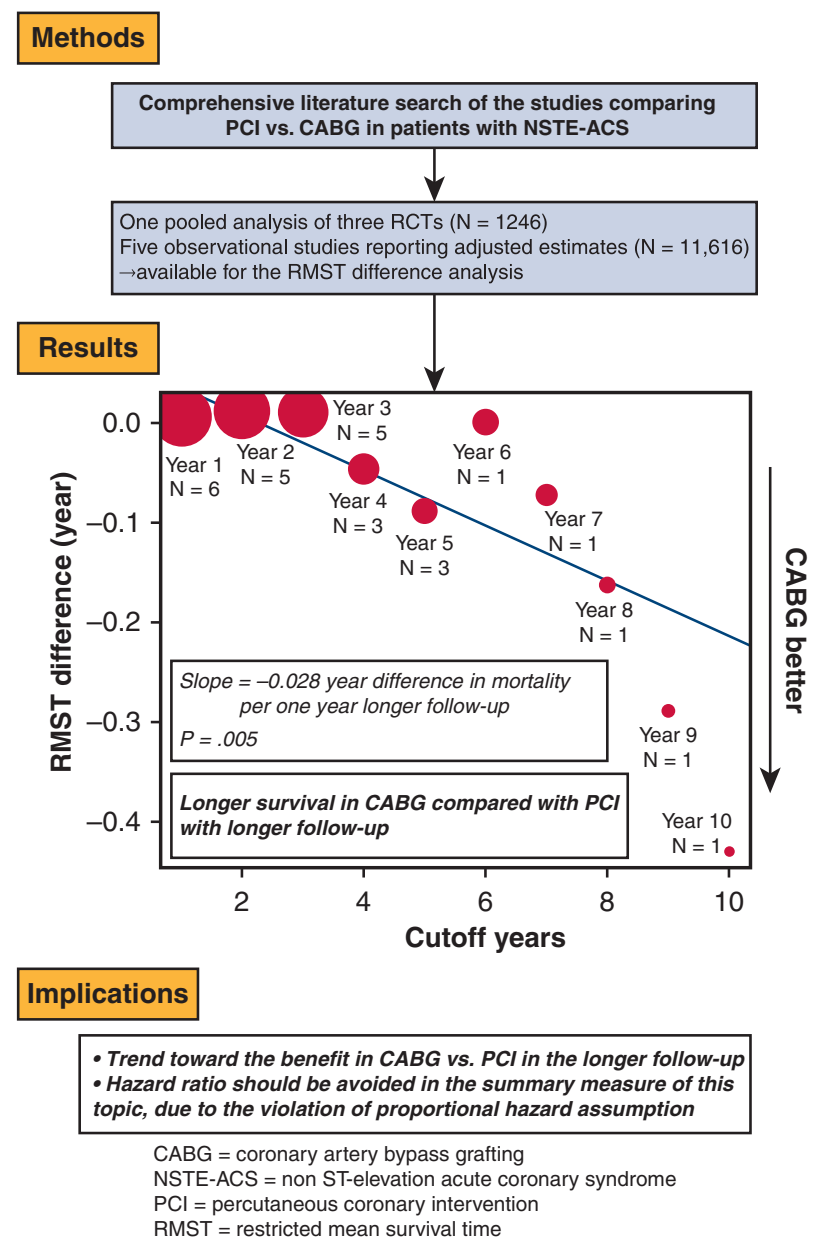

FIGURE 5. Summary of the study. The comprehensive literature search of studies comparing percutaneous coronary intervention $(P C I)$ and coronary artery bypass grafting $(C A B G)$ in patients with non ST-elevation acute coronary syndrome (NSTE-ACS) yielded 1 pooled analysis of 3 RCTs and 8 observational studies in which adjusted estimates were presented. Six of these studies underwent the evaluation of restricted mean survival time (RMST) differences based on the published Kaplan-Meier curves. Meta-regression of RMST differences with the PCI arm as the reference $(y$-axis) on the RMST cutoff years in year 1 to year 10 ( $x$-axis) revealed a significant inverse association (slope, -0.028 year difference per 1 -year longer cutoff; $P=.005$ ). This finding suggests more favorable survival after $\mathrm{CABG}$ compared with PCI with longer follow-up in patients with NSTE-ACS. $N$ indicates the number of studies included in the analysis. Each analysis with different cutoff year was weighted by the inverse variance, represented by the circle area of each analysis. RCT, Randomized controlled trial.

\section{DISCUSSION}

In this systematic review and meta-analysis comparing invasive treatment options for patients with NSTE-ACS, we observed a significant trend toward a benefit of CABG compared with PCI with a longer follow-up with respect to the differences in the pooled RMSTs of all-cause mortality (Figure 5). However, each RMST analysis suffered from moderate heterogeneity. The pooled adjusted HR was null 
with severe heterogeneity, potentially reflecting the violation of the proportional hazards assumption. Subgroup analyses could not explain the source of heterogeneity. Our present findings suggest the advantages of CABG compared with PCI in the long run; however, a large-scale RCT with long-term follow-up is needed to properly address this question.

Our meta-analysis of RCTs and observational studies provides an opportunity to consider the total body of evidence in this area. RCTs of acute coronary syndrome have been criticized as not reflecting real populations and being subject to selection bias. ${ }^{24}$ The analysis of multicenter registries revealed lower 1-year mortality in patients with NSTE-ACS who enrolled in clinical trials compared with those who did not, partly justifying this criticism. ${ }^{25}$ In the setting of observational cohorts targeting NSTEACS, indication bias could be a major concern because, for example, physicians tend to choose PCI for patients with shorter anticipated survival. Thus, we incorporated results from RCTs and adjusted estimates from observational studies to minimize such bias.

We have presented a time-dependent association of treatment strategy and mortality in patients with NSTE-ACS, which is in accordance with previously published evidence. An individual-level meta-analysis of 3 RCTs trials showed a comparable clinical course in the 2 arms at 2 to 3 years after treatment and lower survival in the CABG arm thereafter, while failing to detect a difference in all-cause mortality owing to lower statistical power. ${ }^{7}$ Analysis of the Can Rapid Risk Stratification of Unstable Angina Patients Suppress Adverse Outcomes With Early Implementation of the American College of Cardiology/American Heart Association Guidelines (CRUSADE) registry described a crossing of Kaplan-Meier curves of a composite outcome for patients treated with $\mathrm{PCI}$ and patients treated with $\mathrm{CABG} .{ }^{26}$ Furthermore, the Evaluation of XIENCE versus the Coronary Artery Bypass Surgery for Effectiveness of Left Main Revascularization (EXCEL) trial showed a very similar trend in the primary composite outcome: better with PCI within 3 years after the procedure while subsequently favoring $\mathrm{CABG} .{ }^{27}$ Collectively, the evidence indicates potentially better survival with CABG compared with PCI in patients in whom longer survival is anticipated; however, this conclusion is not definitive without evidence from a large, well-designed RCT.

In general, the advantages of PCI include faster revascularization and a lower risk of periprocedural complications such as stroke, whereas the advantages of CABG may lie in the smaller lifetime ischemic burden and the non-necessity of double antiplatelet therapy. Such different properties might help explain our present observations. Current guidelines recommend immediate invasive treatment with PCI for patients with very-high-risk NSTE-ACS (eg, cardiogenic shock, fatal arrhythmias). ${ }^{3}$ The clinical decision should be individualized for patients at high or intermediate risk, such as those with MVD, left main disease, chronic kidney disease, or other bleeding risks. Discussion by a multidisciplinary team is the ideal scenario. ${ }^{10,11}$ The present evidence does not confer information on the general treatment strategy; instead, it may contribute to the scientific foundation to guide the choice in selected patients with NSTE-ACS.

Our study has some limitations that should be acknowledged. First and foremost, the relevant studies basically reported HRs as the outcome measure, which might not be valid given the potential violation of the proportional hazards assumption. Nevertheless, we were able to reconstruct individual time-to-event data in 6 out of 9 included studies and conduct RMST analyses. Future studies should rely on outcome measures that do not depend on the proportional hazards assumption, such as RMST differences. We leveraged propensity score adjusted estimates in observational studies to account for the indication bias, while residual confounding could not be ruled out. The findings of some studies might not reflect current standard practice, as evidenced by the exclusive use of DESs in the PCI procedures in only 2 studies. Finally, our present findings are based largely on observational studies, and a pragmatic largescale RCT with longer follow-up period is needed to obtain definitive evidence on this topic.

In conclusion, the present systematic review and metaanalysis of RCTs and observational studies suggests more favorable survival after CABG compared with PCI with longer follow-up in patients with NSTE-ACS. The analysis was limited by a violation of the proportional hazards assumption and the unreliability of HR estimates. An outcome measure free from the proportional hazards assumption based on a large-scale RCT with long-term follow-up is needed to provide definitive evidence.

\section{Conflict of Interest Statement}

The authors reported no conflicts of interest.

The Journal policy requires editors and reviewers to disclose conflicts of interest and to decline handling or reviewing manuscripts for which they may have a conflict of interest. The editors and reviewers of this article have no conflicts of interest.

We thank Lu Zhu, MPH, Chun-Han Lo, MD, MPH, and Alina Vodonos Zilberg, PhD for their contribution to this project.

\section{References}

1. Yeh RW, Sidney S, Chandra M, Sorel M, Selby JV, Go AS. Population trends in the incidence and outcomes of acute myocardial infarction. N Engl J Med. 2010; 362:2155-65.

2. Bavry AA, Kumbhani DJ, Rassi AN, Bhatt DL, Askari AT. Benefit of early invasive therapy in acute coronary syndromes: a meta-analysis of contemporary randomized clinical trials. J Am Coll Cardiol. 2006;48:1319-25. 
3. Neumann FJ, Sousa-Uva M, Ahlsson A, Alfonso F, Banning AP, Benedetto U, et al. 2018 ESC/EACTS guidelines on myocardial revascularization. Eur Heart J. 2019;40:87-165.

4. Amsterdam EA, Wenger NK, Brindis RG, Casey DE Jr, Ganiats TG, Holmes DR Jr, et al. 2014 AHA/ACC guideline for the management of patients with non-ST-elevation acute coronary syndromes: a report of the American College of Cardiology/American Heart Association task force on practice guidelines. Circulation. 2014;130:e344-426.

5. Cannon CP, Weintraub WS, Demopoulos LA, Vicari R, Frey MJ, Lakkis N, et al. Comparison of early invasive and conservative strategies in patients with unstable coronary syndromes treated with the glycoprotein IIb/IIIa inhibitor tirofiban. N Engl J Med. 2001;344:1879-87.

6. Goldstein JA, Demetriou D, Grines CL, Pica M, Shoukfeh M, O'Neill WW. Multiple complex coronary plaques in patients with acute myocardial infarction. $N$ Engl J Med. 2000;343:915-22.

7. Chang M, Lee CW, Ahn JM, Cavalcante R, Sotomi Y, Onuma Y, et al. Comparison of outcome of coronary artery bypass grafting versus drug-eluting stent implantation for non-ST-elevation acute coronary syndrome. Am J Cardiol. 2017; 120:380-6.

8. Ram E, Sternik L, Klempfner R, Iakobishvili Z, Peled Y, Shlomo N, et al. Outcomes of different revascularization strategies among patients presenting with acute coronary syndromes without ST elevation. J Thorac Cardiovasc Surg. 2020;160:926-35.e6.

9. Buszman PE, Buszman PP, Bochenek A, Gierlotka M, Gąsior M, Milewski K, et al. Comparison of stenting and surgical revascularization strategy in non-ST elevation acute coronary syndromes and complex coronary artery disease (from the Milestone Registry). Am J Cardiol. 2014;114:979-87.

10. Abdelsattar ZM, Crestanello JA. Commentary: CABG vs PCI in NSTEMI/UA: abbreviated alternatives. J Thorac Cardiovasc Surg. 2020;160:936.

11. Palmerini T, Genereux P, Caixeta A, Cristea E, Lansky A, Mehran R, et al. Prognostic value of the SYNTAX score in patients with acute coronary syndromes undergoing percutaneous coronary intervention: analysis from the ACUITY (Acute Catheterization and Urgent Intervention Triage StrategY) trial. J Am Coll Cardiol. 2011:57:2389-97.

12. Guyot P, Ades AE, Ouwens MJN, Welton NJ. Enhanced secondary analysis of survival data: reconstructing the data from published Kaplan-Meier survival curves. BMC Med Res Methodol. 2012;12:9.

13. McCaw ZR, Yin G, Wei LJ. Using the restricted mean survival time difference as an alternative to the hazard ratio for analyzing clinical cardiovascular studies. Circulation. 2019;140:1366-8.

14. Ahmed K, Jeong MH. Percutaneous coronary intervention with drug-eluting stent implantation versus coronary artery bypass grafting for multivessel coronary artery disease in metabolic syndrome patients with acute myocardial infarction. Am J Cardiol. 2012;109(Suppl):S29.

15. Desperak P, Hawranek M, Hrapkowicz T, Zembala MO, Gąsior M. Comparison of multivessel percutaneous coronary intervention and coronary artery bypass grafting in patients with severe coronary artery disease presenting with nonST-segment elevation acute coronary syndromes. Kardiol Pol. 2018;76:1474-81.
16. Freitas P, Madeira M, Raposo L, Madeira S, Brito J, Brízido C, et al. Coronary artery bypass grafting versus percutaneous coronary intervention in patients with non-ST-elevation myocardial infarction and left main or multivessel coronary disease. Am J Cardiol. 2019;123:717-24.

17. Ben-Gal Y, Mohr R, Feit F, Ohman EM, Kirtane A, Xu K, et al. Surgical versus percutaneous coronary revascularization for multivessel disease in diabetic patients with non-ST-segment-elevation acute coronary syndrome: analysis from the acute catheterization and early intervention triage strategy trial. Circ Cardiovasc Interv. 2015;8:e002032.

18. Jia S, Zhang C, Jiang L, Xu L, Tian J, Zhao X, et al. Comparison of percutaneous coronary intervention, coronary artery bypass grafting and medical therapy in non-ST elevation acute coronary syndrome patients with 3 -vessel disease. Circ J. 2020;84:1718-27.

19. Ramanathan K, Abel JG, Park JE, Fung A, Mathew V, Taylor CM, et al. Surgical versus percutaneous coronary revascularization in patients with diabetes and acute coronary syndromes. J Am Coll Cardiol. 2017;70:2995-3006.

20. Sidik K, Jonkman JN. A comparison of heterogeneity variance estimators in combining results of studies. Stat Med. 2007;26:1964-81.

21. Easterbrook PJ, Berlin JA, Gopalan R, Matthews DR. Publication bias in clinical research. Lancet. 1991;337:867-72.

22. Sedlis SP, Morrison DA, Lorin JD, Esposito R, Sethi G, Sacks J, et al. Percutaneous coronary intervention versus coronary bypass graft surgery for diabetic patients with unstable angina and risk factors for adverse outcomes with bypass: outcome of diabetic patients in the AWESOME randomized trial and registry. J Am Coll Cardiol. 2002;40:1555-66.

23. de Feyter PJ, Serruys PW, Unger F, Beyar R, de Valk V, Milo S, et al. Bypass surgery versus stenting for the treatment of multivessel disease in patients with unstable angina compared with stable angina. Circulation. 2002;105: 2367-72.

24. Majumdar SR, Roe MT, Peterson ED, Chen AY, Gibler WB, Armstrong PW. Better outcomes for patients treated at hospitals that participate in clinical trials Arch Intern Med. 2008;168:657-62.

25. Hutchinson-Jaffe AB, Goodman SG, Yan RT, Wald R, Elbarouni B, Rose B, et al. Comparison of baseline characteristics, management and outcome of patients with non-ST-segment elevation acute coronary syndrome in versus not in clinical trials. Am J Cardiol. 2010;106:1389-96.

26. Roe MT, Li S, Thomas L, Wang TY, Alexander KP, Ohman EM, et al. Long-term outcomes after invasive management for older patients with non-ST-segment elevation myocardial infarction. Circ Cardiovasc Qual Outcomes. 2013;6:323-32.

27. Stone GW, Sabik JF, Serruys PW, Simonton CA, Généreux P, Puskas J, et al. Everolimus-eluting stents or bypass surgery for left main coronary artery disease. N Engl J Med. 2016;375:2223-35.

Key Words: percutaneous coronary intervention, coronary artery bypass grafting, non-ST elevation acute coronary syndrome, meta-analysis, all-cause mortality 


\section{APPENDIX E1: SEARCH STRATEGY IN PUBMED}

("Myocardial Infarction"[Mesh:NoExp] OR "Non-ST Elevated Myocardial Infarction"[Mesh] OR "Acute Coronary Syndrome"'[Mesh] OR acute cardiac infarction*[tiab] OR acute coronary syndrome*[tiab] OR acute heart infarction*[tiab] OR myocardial infarction*[tiab] OR non ST elevated myocardial infarction*[tiab] OR non ST segment elevated myocardial infarction*[tiab] OR non ST segment elevation heart infarction*[tiab] OR non ST segment elevation MI[tiab] OR non ST-elevation $\mathrm{m}^{*}$ [tiab] OR non STEMI [tiab]) AND ("Percutaneous Coronary Intervention"[Mesh: NoExp] OR percutaneous coronary intervention*[tiab] OR revascularisation*[tiab] OR revascularization*[tiab]) AND (“Coronary Artery Bypass"[Mesh] OR aortocoronary artery bypass[tiab] OR coronary artery bypass [tiab] OR coronary artery graft*[tiab] OR coronary bypass[tiab]). 


\section{1 year}

Ahmed $\mathrm{K}$ et al Buszman PE et al Desperak $P$ et al Freitas $\mathrm{P}$ et al Ram E et al

\section{2 year}

Buszman PE et al Desperak $P$ et al Freitas $\mathrm{P}$ et al Ram E et al
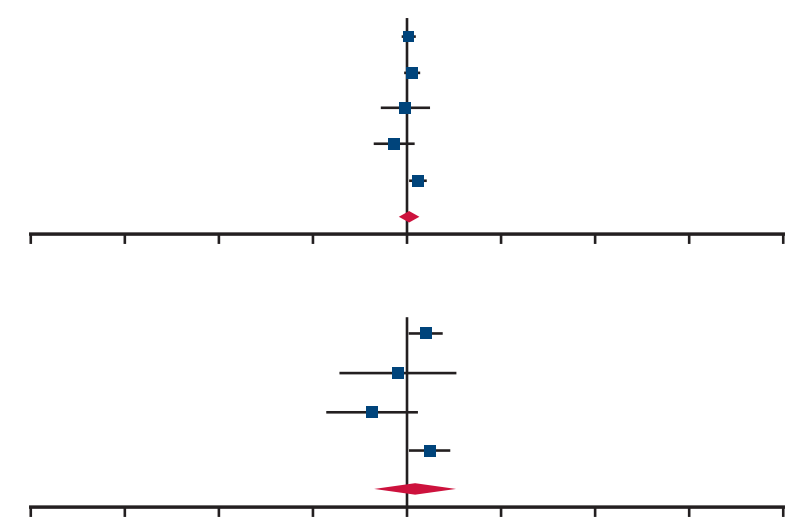

3 year

Buszman PE et al Desperak $P$ et al Freitas $\mathrm{P}$ et al Ram E et al

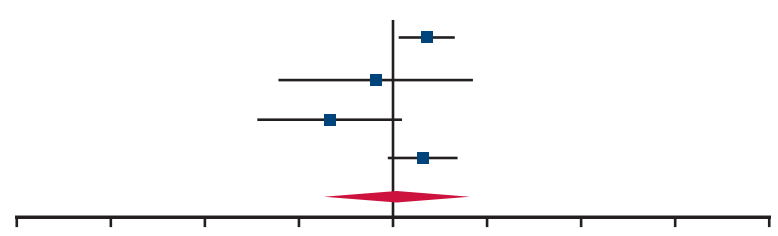

\section{4 year}

Freitas $\mathrm{P}$ et al

Ram E et al

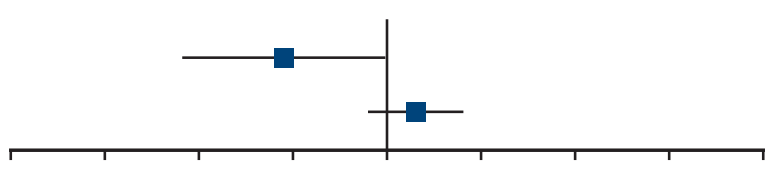

5 year

Freitas $\mathrm{P}$ et al

Ram E et al

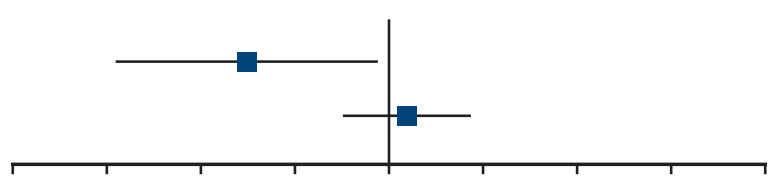

\section{6-10 year}

Ram E et al 6y Ram E et al 7y Ram E et al 8y Ram E et al 9y Ram E et al 10y

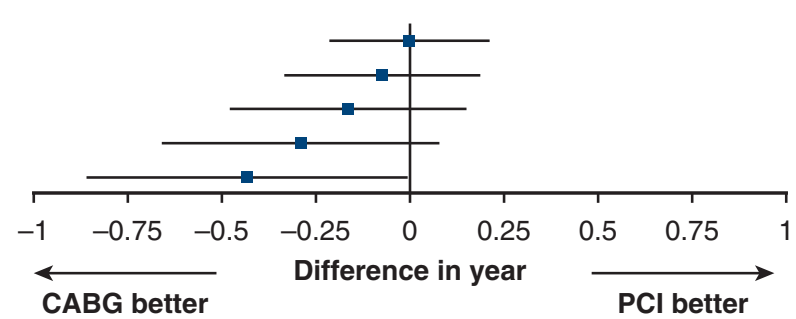

FIGURE E1. Pooled adjusted restricted mean survival time (RMST) differences in mortality in patients with non ST-elevation acute coronary syndrome (NSTE-ACS) after percutaneous coronary intervention $(P C I)$ compared with coronary artery bypass grafting $(C A B G)$, based on 5 observational studies in which RMST data could be computed. The $x$-axis shows the average differences in survival by year until the cutoff year. The analyses were conducted with different cutoff years (years 1-10). The red diamonds represent the summary estimate in the RMST analysis with cutoff year 1 to year 5. The RMST analysis with cutoff year 6 to 10 is based on the study by Ram and colleagues. ${ }^{8}$ 


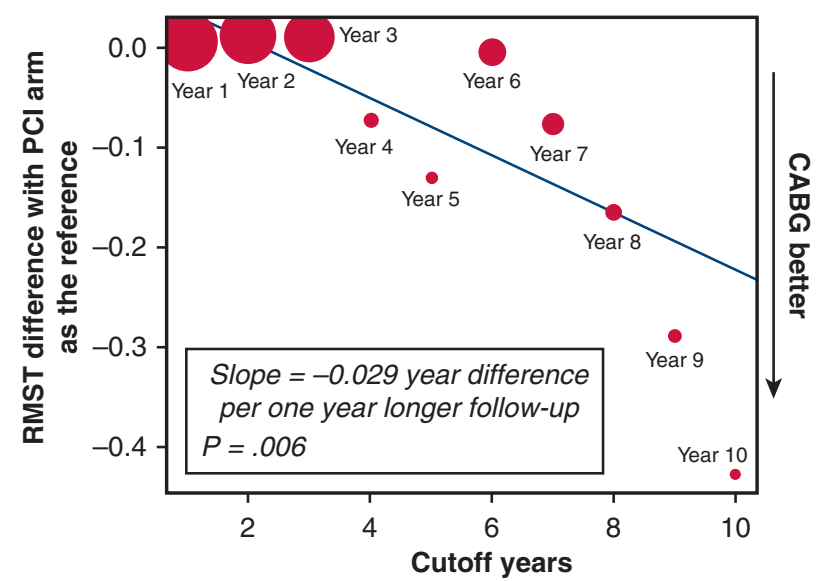

FIGURE E2. Meta-regression of pooled adjusted restricted mean survival time (RMST) differences in different cutoff years in observational studies. The meta-regression shows differences in the adjusted RMST with the percutaneous coronary intervention $(P C I)$ arm as the reference ( $y$-axis) on RMST cutoff years 1 to 10 ( $x$-axis) based on 5 observational studies in which RMST data could be computed. $N$ indicates the number of studies included in the analysis. Each analysis with a different cutoff year was weighted by the inverse variance, represented by the circle area of each analysis. Significant inverse association was observed (slope, -0.029 year difference per 1 -year longer cutoff; $P=.006$ ). $C A B G$, Coronary artery bypass grafting.

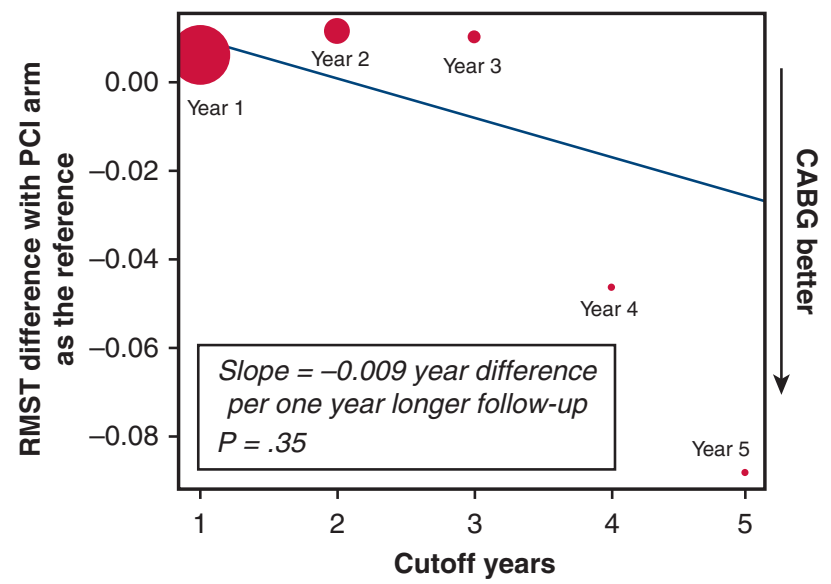

FIGURE E3. Meta-regression of pooled differences in adjusted restricted mean survival time (RMST) in different cutoff years in studies with $\leq 5$ years of follow-up. The meta-regression shows differences in the adjusted RMST with the percutaneous coronary intervention $(P C I)$ arm as the reference ( $y$-axis) in RMST cutoff years 1 to 10 ( $x$-axis) based on 5 studies with $\leq 5$ years of follow-up. $N$ indicates the number of studies included in the analysis. Each analysis with different cutoff year was weighted by the inverse variance, represented by the circle area of each analysis. Significant inverse association was not observed (slope, -0.009 year difference per 1-year longer cutoff; $P=.35$ ). $C A B G$, Coronary artery bypass grafting.

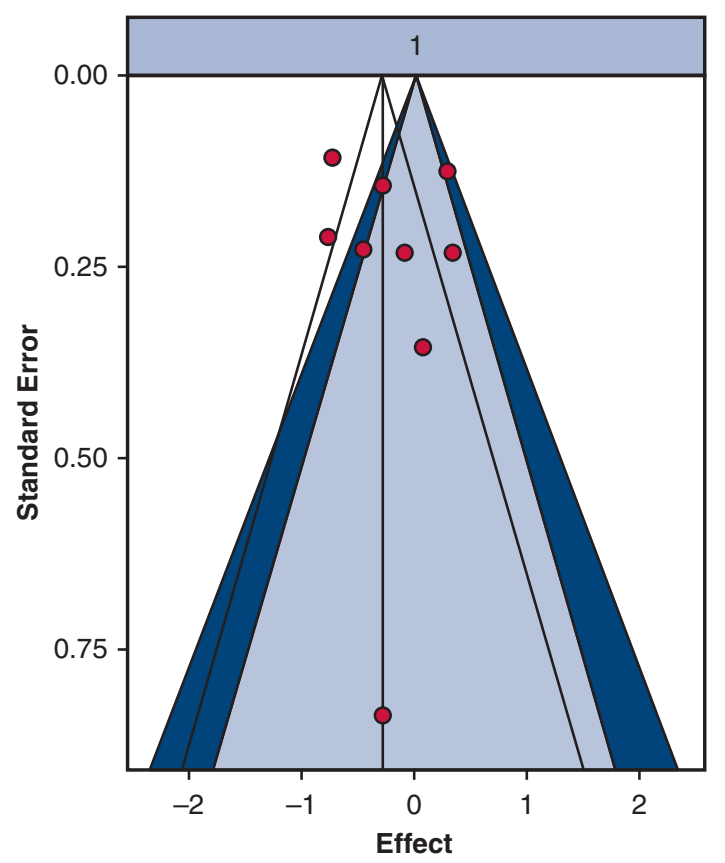

FIGURE E4. A funnel plot of 9 studies incorporated in the pooled analysis of hazard ratios (HRs) showing no apparent asymmetry, suggesting no substantial publication bias. However, the small number of included studies might have led to a lower statistical power of the assessment. 